$$
N>0-32466
$$

\title{
EXPERIMENTAL HYDRODYNAMICS OF THE \\ ACCELERATED TURBULENT BOUNDARY LAYER \\ WITH AND WITHOUT MASS INJECTION
}

By

H. L. Julien, W. M. Kays, and R. J. Moffat

Report HMT-10

This study supported

by

The National Aeronautics and Space Administration NGR 05-020-134

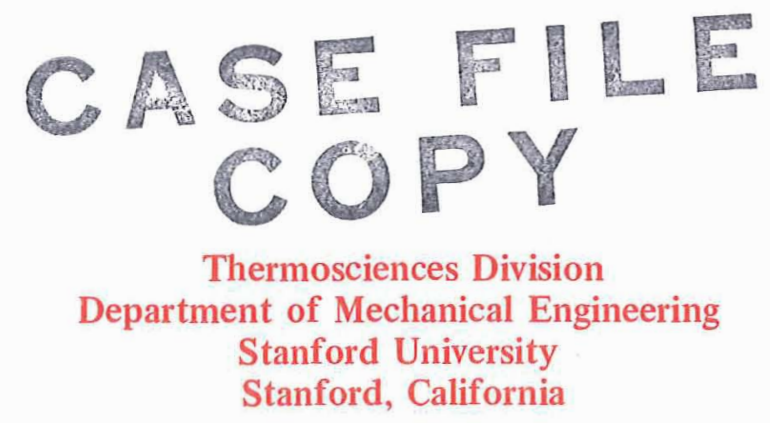

March 1970 
EXPERIMENTAL HYDRODYNAMICS OF THE ACCELERATED TURBULENT BOUNDARY LAYER WITH AND WITHOUT MASS INJECTION

By

H. L. Julien, W. M. Kays, and R. J. Moffat

Report HMT-10

This study supported

by

The National Aeronautics and Space Administration NGR $05-020-134$

The rmosciences Division

Department of Mechanical Engineering

Stanford University

Stanford, California

March 1970 


\section{$\underline{\text { ABSTRACT }}$}

Mean velocity profile data are reported for blown, unblown, and sucked accelerated turbulent boundary layers. The pressure gradients investigated are those corresponding to constant values of the pressure gradient parameter,

$$
K=\frac{\nu}{U_{\infty}^{2}} \frac{d U_{\infty}}{d x}
$$

The two values of $K$ considered in detail are $0.57 \times 10^{-6}$ and $1.45 \times 10^{-6}$. For each pressure gradient, the surface boundary conditions cover a range of constant blowing and sucking fractions from $F=-0.002$ to t0.004.

Velocity profiles corresponding to these accelerated flows are shown to differ substantially from those characteristic of zero pressure gradient flows.

For each case of a constant $K$ acceleration, sequential values of the momentum thickness Reynolds number approach a specific constant, and the velocity distributions near the wall are similar in both wall coordinates and outer coordinates.

Results obtained here can be reproduced by a numerical integration of the boundary layer equations using a modification of the Van Driest damping factor, $\mathrm{A}^{+}$, derived from the data presented here. The $\mathrm{A}^{+}$correlation is presented. 
NOMENCLATURE

$\mathrm{A}^{+} \quad$ function in modified Van Driest mixing-length hypothesis

$B \quad$ blowing parameter $\frac{(\rho V)_{W}}{(\rho U)_{\infty}\left(c_{f} / 2\right)}$

$c_{f} / 2$ friction factor; $\quad c_{f} / 2=g_{c} \tau_{W} /\left(\rho_{\infty} U_{\infty}^{2}\right)$

$\exp \quad$ base of natural logarithms

F blowing fraction; $F=(\rho V)_{W} /(\rho U)_{\infty}$

H profile shape parameter; $\quad H=\frac{\delta_{1}}{\delta_{2}}$

k Von Karman constant

K local pressure gradient parameter; $K=\frac{v}{U_{\infty}^{2}}\left[\frac{d U_{\infty}}{d x}\right]$

l $\quad$ Prandt 1 mixing-length defined by $\tau=\rho l^{2}\left|\frac{\partial u}{\partial y}\right| \frac{\partial u}{\partial y}$

P pressure

$\mathrm{P}^{+} \quad$ pressure gradient parameter; $\mathrm{P}^{+}=\frac{\mathrm{g}_{\mathrm{c}} \mu_{W}}{\rho_{w}^{2} u_{\tau}^{3}}\left(\frac{d P}{d x}\right)=\frac{-K}{\left(c_{f} / 2\right)^{3 / 2}}$

$\mathrm{Re}_{\mathrm{X}} \quad$ Reynolds number based on position along the plate; $\frac{\mathrm{U}_{\infty} \mathrm{X}}{v}$

$\mathrm{Re}_{\mathrm{M}} \quad \mathrm{U}_{\infty} \delta_{2} / v$

$R_{x} \quad$ Integrated $x$-Reynolds number, $R_{x}=\int_{0}^{X} \frac{U_{\infty}}{v} d x$

$U_{\infty} \quad$ velocity in the mainstream direction, ft/sec

u velocity, $\mathrm{ft} / \mathrm{sec}$

$u^{+} \quad$ dimensionless velocity; $u^{+}=u / u_{\tau}$ 
$u_{\tau}$ shear velocity; $u_{\tau}=\sqrt{\tau_{w} g_{c} / \rho}, f t / s e c$

v velocity perpendicular to the wall, $\mathrm{ft} / \mathrm{sec}$

$\mathrm{v}_{\mathrm{W}}^{+}$dimensionless blowing velocity; $\mathrm{v}_{\mathrm{W}}^{+}=\mathrm{v}_{\mathrm{W}} / \mathrm{u}_{\tau}$

$x$ distance along the plate in the flow direction, inches

y distance along a line perpendicular to the plate, inches, $y=0$ at plate surface

$\mathrm{y}^{+} \quad$ dimensionless distance; $\mathrm{y}^{+}=\mathrm{yu}_{\tau} / \nu$

$\delta$ boundary layer thickness; y at $\frac{u}{U_{\infty}}=0.99$

$\delta_{1}$ displacement thickness;

$$
\delta_{I}=\int_{0}^{\infty}\left(I-\frac{\rho u}{\rho_{\infty} U_{\infty}}\right) d y
$$

$\delta_{2}$ momentum thickness of the boundary layer;

$$
\delta_{2}=\int_{0}^{\infty} \frac{\rho u}{\rho_{\infty} \bar{U}_{\infty}}\left(1-\frac{u}{U_{\infty}}\right) d y
$$

$\lambda \quad$ outer region mixing-length constant

$\mu \quad$ dynamic viscosity, $1 b_{m} /($ sec $f t)$

$v \quad$ kinematic viscosity, $\mathrm{ft}^{2} / \mathrm{sec}$

$\rho \quad$ density, $1 b_{m} / f t^{3}$

$\tau \quad$ shear stress, $\mathrm{Ib}_{\mathrm{f}} / \mathrm{ft} \mathrm{t}^{2}$

$\tau^{+} \quad$ dimensionless shear stress; $\tau^{+}=\tau / \tau_{\mathrm{W}}$ 
Subscripts

$t$ denotes turbulent contribution

w wall condition

$\infty \quad$ free-stream condition 


\section{INTRODUCTION}

The turbulent boundary layer with non-zero normal velocity at the surface, $v_{w}$, is of considerable practical interest. Injection of fluid at a surface is frequently used for thermal protection, and suction is used for boundary layer control. In many applications the mainstream fluid is accelerating or decelerating and the combined effects of transpiration at the surface, and acceleration at the main flow, must be considered. A survey of the existing data on the turbulent boundary layers where transpiration and mainstream acceleration are present indicates a need for further work. Existing turbulent boundary layer "theory" presently relies heavily on experimental results; accurate and well documented velocity measurements are necessaíry as a test for any theoretical developments.

The present paper is restricted to boundary layer flows characterized by constant values of the acceleration parameter $K\left(K=\frac{v}{U_{\infty}^{2}} \frac{d U_{\infty}}{d x}\right)$, and blowing fraction $F\left(F=\frac{(\rho V)_{W}}{(\rho U)_{\infty}}\right)$. The flows considered are two-dimensional, constant property flows over an aerodynamically smooth surface, as nearly as the apparatus permits.

Review of Previous Experimental Work

Although in recent years a number of experimental hydrodynamic investigations have been concerned with transpired or accelerated boundary layers, only two are known to consider the combined effects. Each dealt only with blown layers, and neither presented enough experimental data to adequately represent the boundary layer characteristics. 
Romanenko and Kharchenko [1] recorded friction factor and Stanton number data for some combined cases, but did not present profiles of velocity or temperature. McQuaid [2] reports two combined blowing and accelerated runs. Using friction factors corresponding to stevenson's inner law [3], McQuaid was able to predict momentum thickness distributions which agreed well with the experimentally determined distributions, but there is a question as to whether this is a sensitive test of friction factor when blown boundary layers are considered. Accelerations were relatively small compared to those considered here.

Experimental investigations have shown that significant changes in boundary layer characteristics result from acceleration even on an impermeable surface. Launder and Stinchcombe [4] studied flows with accelerations at constant $K$ in which the local momentum thickness Reynolds number, $R e_{M}$, approached an asymptotic limit. The velocity profiles exhibited similarity. Tests were run at $K=0.7 \times 10^{-6}, 1.25 \times 10^{-6}$, and $3 \times 10^{-6}$ and, as $K$ was increased, a continuous shift from a typical non-accelerated turbulent profile was shown. This shift was characterized by a thickening of the viscous region resulting in an upward displacement of the velocity profile in the logarithmic region on $\mathrm{u}^{+}, \mathrm{y}^{+}$coordinates, and a simultaneous decrease in the extent and strength of the wake region. Later experiments of Launder and Jones [5] do not corroborate the quantitative results of Launder and stinchcombe, but the same qualitative conclusions were found to apply. This behavior in the inner regions of the boundary layer is consistent with the findings of the structure studies of Kline, Reynolds, Schraub 
and Runstadler [6]. They found that a decrease in the bursting rate of turbulent disturbances originating at the wall is associated with an increase in $K$.

The experiments of Badri, Naroyanan and Ramjie [7] were concerned with both constant and variable $\mathrm{K}$ flows, and demonstrated the same profile behavior. The experiments of Patel and Head [8] were concerned with boundary layer flows for which $K$ was strongly varying, but otherwise showed the same effects.

The case of transpiration with constant free-stream velocity has been fairly completely studied (see for example Mc quaid [2], and simpson [9]). It is evident that the case of acceleration with no transpiration has been only incompletely studied, and the combined case of transpiration with acceleration has been virtually untouched. In view of the substantial structural changes observed for either of these effects alone, it is extremely difficult to anticipate the influence of the combination of transpiration and acceleration.

\section{Description of an Asymptotic Boundary Layer}

The two-dimensional momentum integral equation can be presented in the form,

$$
\frac{d e_{M}}{d R e_{X}}=\frac{c_{f}}{2}-R e_{M}(H+1) K+F
$$

where $\quad d e_{X}=\frac{U_{\infty}}{v} d x$. 
For constant values of $K$ and $F$, the possibility exists that the boundary layer will develop such that the terms on the right side of equation (I) will balance, forcing the derivative $\frac{a R e_{M}}{d R e_{X}}$ to zero. Such a boundary layer will be termed asymptotic in the regime where $\mathrm{Re}_{\mathrm{M}}$ is constant. There is no question that such boundary layers exist for laminar flows; in fact, they form a family of similarity solutions. Turbulent boundary layers also behave in this manner. Such boundary layers exhibit both inner and outer similarity, with $c_{f} / 2$ and $H$ being constant, as weIl as $\operatorname{Re}_{M}$.

The experiments reported here were restricted to asymptotic and near asymptotic boundary layers for purposes of convenience. For these flows, equation (1) yields one method of estimating friction factor since the derivative, $\frac{d R \epsilon_{M}}{d R e_{X}}$, represents a correction to the asymptotic form of equation (1). This is a desirable characteristic since direct measurement of friction factor was not possible on the apparatus used. These flows are also characterized by constant values of the blowing parameters $\mathrm{B}$ and $\mathrm{V}_{\mathrm{W}}{ }^{+}$, as well as $\mathrm{P}^{+}$, which are desirable characteristics in the formulation of data correlations.

\section{Objectives of the Present Work}

The overall intent of the work presented here was to investigate the fluid dynamic behavior of the turbulent boundary layer where the combined effects of transpiration and acceleration are present. The range of blowing, suction, and acceleration considered covers many practical applications where turbulent boundary layer 
theory is appropriate. The particular objectives of this paper are:

(1) To present mean velocity profile data taken on the Stanford Heat and Mass Transfer Apparatus;

(2) To present skin friction results obtained from the mean velocity profiles;

(3) To represent the combined effects of transpiration and acceleration in the form of a mixing-length model based on the Van Driest damping function.

\section{E.XPERIMENTAL APPARATUS}

The Stanford Heat and Mass Transfer Apparatus was used in these experiments. Since this is described in detail by Moffat and Kays $[10,11]$, only a brief description will be presented here.

The apparatus consists of a 24-segment porous plate, 8feet long and 18-inches wide. The plate forms the lower surface of a test duct of rectangular cross-section, 20 inches wide and 6 inches high at the inlet end of the duct. The upper surface is adjustable to achieve any desired free-stream velocity aistribution along the duct. The plates are 1/4-inch thick, smooth to the touch and uniform in porosity within \pm 6 percent in the six-inch span along the test duct centerline where velocity profiles are taken. Separate mainstream and transpiration blowers provide the system with air, while heat exchangers are used to control air temperature. Conventional temperature and flow rate instruments were used to monitor the operation of the apparatus. 
Mean velocity profiles were taken with stagnation pressure probes similar to those used by Simpson [9] and using the same manual traversing equipment. The probes had flattened mouthes, 0.012 inch by $0.035 \mathrm{inch}$. They were attached to micrometerdriven traversing instruments fastened to a rigid support frame. Dynamic pressures were measured with calibrated inclined manometers.

Static pressure taps were located at 2-inch intervals along one side-wall of the test section. Free-stream static pressure was shown to be equal to that sensed by the side wall taps by using static pressure probes in each accelerated flow. All recorded data were taken using the side-wall taps.

\section{QUALIFICATION OF THE APPARATUS}

It has already been reported by Simpson, Moffat and Kays [12] that the apparatus meets the requirements of the idealized Ilow model for constant free-stream velocity: i.e., steady, twodimensional, constant property flow over a smooth uniformly permeable flat plate. Acceleration emphasizes other requirements, beyond those of the flat plate. Those effects are given additional consideration [13] in the present experiments. These are summarized below.

Free-stream turbulence intensities were found to be between 0.8 and 1.2 percent at the inlet conditions although velocity profiles for impermeable flat-plate flows satisfy Coles' criterion for "normal" boundary layers [14].

Surface roughness effects were investigated by a series of tests at 42,86 and $126 \mathrm{fps}$. In the data for 42 and $86 \mathrm{fps}$, mean 
velocity profiles exhibited $u^{+}$vs. $\mathrm{y}^{+}$similarity near the wall $\left(\mathrm{Y}^{+}<150\right)$, when wall shear was determined from sequential velocity profiles by means of the momentum integral equation. In the data for 126 fps a slight drop in $u^{+}$was observed for the velocity profiles, so tests were restricted to velocities less than $86 \mathrm{ft} / \mathrm{sec}$. Plate roughness elements, considered as half the particle diameter, were calculated to remain inside the viscous region of the boundary layer as best as this can be determined.

Accelerating flows are necessarily accompanied by streamwise variations in static pressure. Variations in the transpiration mass flux through each plate due to these variations were found to be negligible. For each static pressure distribution in the experiments reported no temperature gradients were found in the plates when they were heated, with either blowing or suction applied. The pressure drop through each plate was found to be not less than 10 times the drop across the span of any plate at the lowest blowing fraction of 0.001 .

Two-dimensionality of a flow can only be determined by elaborate probing of the boundary layer. This was not done, but secondary evidence was obtained by comparing enthalpy thickness derived from plate heat transfer measurements with values determined from temperature and velocity profiles. Such checks were made possible by thermal data obtained on the apparatus for the same conditions as the hydrodynamic data [15]. Energy balance checks showed agreement within 8 percent for all blowing runs. This is within the uncertainty calculated for the enthalpy thickness integrals using the method of Kline and McClintock [16]. 
In view of these results, the observed behavior of the data presented is felt to fairly represent the effects of acceleration and transpiration.

\section{EXPERIMENTAL DETERMINATION OF FRICTION FACTOR}

Determination of friction factors to an acceptable degree of accuracy from velocity profile measurements is extremely difficult at best. When the flow is accelerating, and there is transpiration at the wall, the difficulties are compounded. There is no turbulent "law of the wall" with which to compare profiles; in fact an important objective of the experiments was to attempt to establish a "law of the wall" under these conditions.

There are two physical principles which must hold; (a) the momentum integral equation of the boundary layer must be satisfied, and (b) in the region very near the wall the turbulent shear stresses should be small relative to viscous shear; i.e., a velocity equation based on viscous shear alone must be satisfied. However, there are considerable experimental uncertainties in using either of these principles to extract friction factors from the data. Eq. (I) can be solved for $c_{f} / 2$, but uncertainty in the term dRe ${ }_{M} / d R e_{X}$ (which is never quite zero) coupled with uncertainty as to the degree of two-dimensionality of the flow, result in uncertainties in $c_{f} / 2$ of at least \pm 15 percent for the unblown runs, and as much as \pm 50 percent for the highly blown runs. On the other hand, the use of a viscous sublayer equation as suggested in (b) above, is subject to uncertainties resulting from the use of a probe which is "Iarge" compared to the boundary layer. 
A third principle, which can only really be applied subjectively, is that the final results must be internally consistent. Abrupt changes in $c_{f} / 2$ are not expected when all of the external parameters are held close to constant, and the variation of $c_{f} / 2$ with the external parameters is expected to be continuous. The inner region of the velocity profiles, when plotted on wall coordinates $\left(\mathrm{u}^{+} \mathrm{vs} \cdot \mathrm{y}^{+}\right)$should collapse together when $\mathrm{P}^{+}$and $\mathrm{v}_{\mathrm{w}}^{+}$are nearly constant, regardless of whether the profile is obtained very near the asymptotic condition, or considerably before it.

The procedure used here to determine $c_{f} / 2$ was based on the momentum integral method with the results adjusted inside the uncertainty interval to obtain similarity in the sublayer region $\left(\mathrm{y}^{+}<15\right)$ in $\mathrm{u}^{+}, \mathrm{y}^{+}$coordinates.

The first estimates of $\mathrm{c}_{\mathrm{f}} / 2$ were determined by evaluating the terms of Equation (1) at each of four stations inside the constant $K$ region: note that the most difficult term to evaluate, $d R e_{M} / d R e_{X}$, is nearly zero for the runs reported here (it would be identically zero for a perfectly asymptotic flow). Data from each of the four profiles were then reduced to $\mathrm{u}^{+}, \mathrm{y}^{+}$ coordinates using the momentum-based values of $c_{f} / 2$ and compared with the laminar sublayer equation predictions for the same conditions of blowing and acceleration. A single sublayer prediction was judged appropriate for each run, covering four profiles since the sublayer equations, Equations 3 and 4, are not highly sensitive to the value of $c_{f} / 2$ and the momentum based values of $c_{f} / 2$ did not vary much along the acceleration region 


$$
\begin{gathered}
\mathrm{u}^{+}=\frac{1}{\mathrm{v}_{\mathrm{W}}^{+}}\left(1+\frac{\mathrm{P}^{+}}{\mathrm{v}_{\mathrm{W}}^{+}}\right)\left[\exp \left(\mathrm{v}_{\mathrm{W}}^{+} \mathrm{y}^{+}\right)-1\right]-\mathrm{P}^{+} \mathrm{y}^{+} \\
\text {for } \mathrm{v}_{\mathrm{W}}^{+} \neq 0.0
\end{gathered}
$$

and,

$$
\begin{aligned}
& u^{+}=\mathrm{y}^{+}\left[1+\frac{\mathrm{p}^{+} \mathrm{y}^{+}}{2}\right] \\
& \text { for } \mathrm{v}_{\mathrm{w}}^{+}=0.0
\end{aligned}
$$

These equations result from integration of the X-momentum equation of the boundary layer, neglecting $X$-derivatives of velocity and turbulent shear stresses.

In general, the profile data fell close to the sublayer prediction inside $\mathrm{y}^{+}$of 15 , although not exactly on the curve. Part of the difference was attributed to random uncertainties in the momentum-based friction factor and part to the systematic effect of the velocity gradient on the apparent location of the pitot probe when near the wall. No attempt was made to evaluate wall-displacement effects on the probe readings. For each run, one or more reference profiles were selected and their $c_{f} / 2$ values fixed exactly at the momentum based value. Values of $\mathrm{c}_{\mathrm{f}} / 2$ for the other profiles were then adjusted to force coincidence with these reference profiles in the sublayer region. This is an attempt at removing the random component of the uncertainty in $c_{f} / 2$ by smoothing the momentum based results thru the sublayer equation. It does not constitute a true sublayer 
method, since no effort was made to eliminate the effects of shear and wall proximity from the data. In all cases the $c_{f} / 2$ values stayed within the calculated uncertainty intervals surrounding the original estimates of skin friction based on the momentum equation.

For the cases of no transpiration, and constant free-stream velocity, a further consideration was that the results should be consistent with the "Iaw of the wall" established by simpson [9] from measurements on the same apparatus:

$$
u^{+}=\frac{1}{0.44} \ln \mathrm{y}^{+}+5.55
$$

The final skin friction results for 58 out of 68 profiles fall within \pm 10 percent of the results obtained from the momentum integral method, and all of the profiles presented in this paper are within the \pm 10 percent interval. Because of the degree of subjective interpretation involved, the velocity profiles are presented not only in terms of $\mathrm{u}^{+} \mathrm{vs} . \mathrm{y}^{+}$, but also in their original form, $u / U_{\infty} v s . y / \delta$. The authors feel that the true values of $c_{f} / 2$ cannot differ from the reported values by more than \pm 10 percent if serious internal inconsistencies are not allowable.

\section{EXPERIMENTAL RESULTS}

The experimental data consist of mean velocity profiles obtained in near-asymptotic boundary layer flows where the pressure gradient parameter $K$ and blowing fraction $F$ are maintained constant. Data are presented for two pressure 
gradients: $K=0.57 \times 10^{-6}$, and $1.45 \times 10^{-6}$. For each pressure gradient, the conditions investigated cover a range of uniform blowing fractions from $F=-0.002$ to to.004. A complete description of these data is presented by Julien [13] along with other data covering $\mathrm{K}=0.77 \times 10^{-6}$ and data for higher blowing fractions than reported here (up to $F=+0.006$ ). The data selected for presentation here are believed representative of the processes involved.

Selected data are summarized in Figures 1 through 6 and are also presented in Table 1 for the convenience of those wishing quantitative values for comparison with predictions.

The velocity profiles are presented in wall coordinates $\mathrm{u}^{+}$ vs. $\mathrm{y}^{+}$) in Figures 1 through 6 . For purposes of comparison, the "Iaw of the wall", with constants proposed by Simpson [9], is also presented on each of the graphs. The profile obtained in the constant free-stream velocity approach region is presented along with the profiles obtained in the pressure gradient region of the duct.

It is shown in Figures 1 and 2 that, for the impermeable wall case, $F=0$, the inner regions of the boundary layer respond rapidly to the imposed pressure gradient and assume a unique distribution corresponding to a given value of $K$. Similar inner region profiles exist in asymptotic boundary layer flows, and the shape of the profile is dependent upon the value of the local pressure gradient parameter $K$.

Two characteristics of these impermeable wall boundary layer flows are shown in inner region coordinates: (1) The profiles depart from the flat plate "Iaw of the wall" by an upward displacement in the logarithmic region, and (2) the wake region is substantially diminished. The degree of upward displacement in 
the logarithmic region increases with $K$. This behavior can be interpreted as an increase in the thickness of the "viscous sublayer" region. The diminished wake is a direct result of the low shear stress in the outer regions of the layer, a characteristic associated with favorable pressure gradients.

In Figures 3 and 4, similar effects of acceleration are shown to exist when there is blowing at the wall $(F=0.004)$. An upward displacement of the "logarithmic" region is noted, together with a reduction of the wake. The wake region shows a more substantial decrease than the unblown layer, indicating a greater increase in friction factor due to acceleration.

The boundary layer flows in the case of suction at the wall, $F=-0.002$, are shown in Figures 5 and 6 . The upward displacement of the logarithmic region, relative to the sucked but unaccelerated layer, is now much more substantial, and the characteristic shape of a laminar profile (roundness of profile) is approached. It appears that a turbulent boundary layer is still obtained and is approaching an equilibrium state, but for the case on Figure 6 laminarization is apparently closely approached. In the outer regions of the boundary layer, similar profile development was attained for all blowing and sucking fractions considered [13]. This similarity is found in "velocity-defect coordinates" $\left(\frac{U_{\infty}-u}{u_{\tau}}\right.$ vs. $\left.y / \delta\right)$ as well as $u / U_{\infty}$ vs. $y / \delta$. The outer region similarity, coupled with the similar conclusion relating to the inner regions, confirms the existence of completely similar profiles in asymptotic turbulent boundary layers. 


\section{EMPIRICAL REPRESENTATION OF THE DATA}

The primary reason for obtaining and presenting data of the type discussed in this paper is to provide a basis for extending turbulent boundary theory and thereby contributing to turbulent boundary layer prediction methods. The velocity profiles and accompanying estimates of $c_{f} / 2$ are presented in sufficient detail so that, hopefully, other workers can use the data as a proving ground for either existing or new theoretical models of the turbulent momentum exchange process near a wall.

Although new theoretical models will undoubtedly be developed, the authors have found that all of the results presented here, together with the complete set of data on the transpired turbulent boundary layer with constant $U_{\infty}$ presented by Simpson [9], can be quite adequately reproduced by a relatively simple mixing-length correlation.

The major influence of both transpiration and acceleration is evidently in the sublayer region. Acceleration apparently increases the effective sublayer thickness (in $\mathrm{y}^{+}$coordinates, not necessarily real distance), as does blowing. A simple twc. layer model of the boundary layer, with the laminar sublayer thickness treated as a function of $\mathrm{V}_{\mathrm{W}}^{+}$and $\mathrm{P}^{+}$, and using elementary PrandtI mixing-length theory outside of the laminar sublayer, works remarkably well. However, for computational convenience, and perhaps esthetic reasons as well, the Van Driest mixing-length hypothesis is more attractive, and will be used here as a method for correlating the results. No claim will be made regarding a theoretical basis for the Van Driest hypothesis: 
it is merely providing a framework for an empirical correlation of experimental data. The scheme used is as follows:

The total shear stress is considered to consist of the sum of a laminar component and a turbulent component. The latter, $\tau_{t}$, is calculated from the Prandtl mixing-theory equation,

$$
\tau_{t}=\rho l^{2}\left|\frac{\partial u}{\partial y}\right| \frac{\partial u}{\partial y}
$$

Equation (6) is used all the way to the wall, and the mixinglength, $\ell$, is assumed to vary from zero at the wall to ky farther out, according to the following relation.

$$
l=\operatorname{ky}\left[1-\exp \left(\frac{-y^{+} \sqrt{\tau^{+}}}{A^{+}}\right)\right]
$$

$\mathrm{A}^{+}$is an empirical constant to which Van Driest [17] originally assigned a value 26. It is essentially an effective laminar sublayer thickness. The argument of the exponential is frequently expressed as simply $-\mathrm{y}^{+} / \mathrm{A}^{+}$; the product $\mathrm{y}^{+} \sqrt{\tau^{+}}$is the Iocal value of $\mathrm{y}^{+}$rather than the value based on wall shear stress. This alteration has been used by numerous workers because it has the effect of diminishing the sublayer region for blowing, and increasing it for acceleration; in fact, it provides all of the trends of behavior observed. $\mathrm{y}^{+} \sqrt{\tau^{+}}$is also approximately proportional to the "Iocal Reynolds number of turbulence" which perhaps provides a further explanation of the significance of $\mathrm{A}^{+}$. However, despite the fact that evaluation of $\mathrm{y}^{+}$at the Iocal shear stress (i.e., $\mathrm{y}^{+} \sqrt{\tau^{+}}$) gives the right trends, the 
experimental data indicate that a still stronger effect is needed for both transpiration and acceleration. Thus the empirical correlation to which we have been referring is a correlation of $\mathrm{A}^{+}$as a function of $\mathrm{V}_{\mathrm{W}}^{+}$and $\mathrm{P}^{+}$.

It should be further noted that eq. (7) is only expected to apply in the region of the boundary layer near the wall, and not in the "wake" region. The latter is quite adequately handled, at least for equilibrium boundary layers, by a method to be described later.

In order to evaluate $\mathrm{A}^{+}$from experimental velocity profiles it is first necessary to determine $\tau^{+}$. For asymptotic accelerating boundary layers the similarity of velocity profiles leads to,

$$
\tau^{+}=1+\mathrm{U}^{+} \mathrm{v}_{\mathrm{w}}{ }^{+}+\mathrm{P}_{\mathrm{y}}^{+}\left[1-\frac{1}{\mathrm{y}} \int_{0}^{\mathrm{y}}\left(\frac{\mathrm{u}}{\mathrm{U}_{\infty}}\right)^{2} d \mathrm{y}\right]
$$

Equations (6) through (8) were used to solve for the values of $\mathrm{A}^{+}$necessary to predict the experimental velocity profiles in the region far enough from the wall so that the flow was essentially fully turbulent, but not so far that the wake was included. Essentially this involved matching at about $\mathrm{y}^{+}=100$, although this also resulted in a good match over virtually the entire inner region.

The resulting values of $A^{+}$are presented in Table ${ }^{2}$ as functions of $\mathrm{P}^{+}$and $\mathrm{V}_{\mathrm{W}}^{+}$.

$\mathrm{A}^{+}$was also extracted from the data of Simpson [9], obtained on the same apparatus for a wide range of transpiration with constant 
$U_{\infty}$ - Simpson's results can be adequately represented by,

$$
A^{+}= \begin{cases}26.0-88.0 \mathrm{v}_{\mathrm{W}}^{+}+210.0\left(\mathrm{v}_{\mathrm{W}}^{+}\right)^{2} & \mathrm{v}_{\mathrm{W}}^{+} \leq 0 \\ 26.0-88.0 \mathrm{v}_{\mathrm{W}}^{+}+110.0\left(\mathrm{v}_{\mathrm{W}}^{+}{ }^{+}\right)^{2} & \mathrm{v}_{\mathrm{W}}^{+} \geq 0\end{cases}
$$

A simpler alternative expression which fits simpson's results nearly as well is,

$$
\mathrm{A}^{+}=\frac{4.42}{\left(\mathrm{v}_{\mathrm{W}}^{+}+0.17\right)} \quad\left(\text { for all } \mathrm{V}_{\mathrm{W}}^{+}\right)
$$

Analysis of the profiles in the wake region for both the present results for asymptotic accelerations, and Simpson's results, indicates that a constant mixing-length is an adequate approximation. This scheme has been used extensively in the past; it works particularly well for accelerated flows simply because the shear stress is so low in the wake that high accuracy is not needed.

The wake correlation derived from the present (and simpson's) results is:

$$
\text { For } y / \delta>\lambda / k \quad \ell=\lambda \delta
$$

where,

and

$$
\begin{aligned}
\lambda & =0.25 \operatorname{Re}_{\mathrm{m}}^{-0.125}[1-67.5 \mathrm{~F}] \text { for } \lambda>0.085 \\
& =0.085 \text { otherwise }
\end{aligned}
$$

For $\mathrm{y} / \delta<\lambda / \mathrm{k}$ eq. (7) is to be used.

Equations (6) through (11), when used in a finite-difference turbulent boundary layer prediction program, will reproduce very adequately all of the experimental data presented in this paper, and by Simpson [9]. 


\section{SUMMARY AND CONCLUSIONS}

(1) Experimental mean velocity profile data have been presented for constant $K$ accelerated turbulent boundary layers with and without transpiration. Skin friction results are included along with shape factors and Reynolds numbers.

(2) It is demonstrated that an acceleration at constant $K$ with transpiration leads to an asymptotic boundary layer having inner and outer similarity and constant $c_{f} / 2$, $H$, and $\operatorname{Re}_{M}$.

(3) Acceleration apparently causes an increase in the thickness of the viscous sublayer. Blowing opposes this effect, while suction enhances it. It seems evident that strong acceleration and/or strong suction will lead to a complete laminarization of the boundary layer, but neither the acceleration nor the suction were carried this far in the present experiments.

(4) An empirical correlation of the data is presented in the form of a correlation of the damping constant $\mathrm{A}^{+}$in the Van Driest mixing-length hypothesis. 


\section{ACKNOWLEDGEMENT}

This work was supported by the National Aeronautics and Space Administration, Grant NGR-05-020-134. The authors would particularly like to thank Mr. Robert W. Graham of Lewis Laboratories for his interest. 


\section{REFERENCES}

1. Romanenko, P. N., and Karchenko, V. N., "The Effects of Transverse Mass Flow on Heat Transfer and Friction Drag in a Turbulent Flow of a Compressible Gas Along an Arbitrarily Shaped Surface," Int. Jn. of Heat and Mass Transfer, Vol. 6, No. 8, (1963).

2. McQuaid, J., "Incompressible Turbulent Boundary Layers with Distributed Injection," Ph.D. thesis, Cambridge Univ., (1966).

3. Stevenson, T. N., "A Law of the Wall for Turbulent Boundary Layers with Suction or Injection, "Cranfield College of Aero. Report 166, (1963).

4. Launder, B. E., and Stinchcombe, H. S., "Non-Normal Similar Turbulent Boundary Layers," Mechanical Engr. Dept., Imperial College, London, (1967).

5. Launder, B. E., and Jones, W. P., "On the Prediction of Laminarization," Mechanical Engr. Dept., Imperial College, London, (1968).

6. Kline, S. J., Reynolds, W. C., Schraub, F. A., and Runstadler, P. W., "The Structure of Turbulent Boundary Layers," J. Fl. Mech., Vol. 30, part 4, p. 74I, (1967).

7. Badri Narayanan, M. A., and Ramjie, V., "On the Criteria for Reverse Transition in a Two-Dimensional Boundary Layer Flow," Report No. AE 68 FM 1, Dept. of Aero. Engrg., Indian Inst. of Science, (1968).

8. Patel, V. C., and Head, M. R., "Reversion of Turbulent to Laminar Flow," J. Fl. Mech., Vol. 34, part 2, p. 371, (1968).

9. Simpson, R. L., "The Turbulent Boundary Layer on a Porous Plate: An Experimental study of the Fluid Dynamics with Injection and Suction," Ph.D. thesis, Thermosciences Division, Mechanical Engr. Dept., Stanford Univ., (1967): available from Univ. Microfilms, Ann Arbor, Mich.

10. Moffat, R. J., "The Turbulent Boundary Layer on a Porous Plate: Experimental Heat Transfer with Uniform Blowing and Suction," Ph.D. thesis, Thermosciences Division, Dept. of Mechanical Engr., Stanford Univ., (1967); available from Univ. Microfilms, Ann Arbor, Mich.

11. Moffat, R. J., and Kays, W. M., "The Turbulent Boundary Layer on a Porous Plate: Experimental Heat Transfer with Uniform Blowing and Suction," Int. Jn. of Heat and Mass Transfer, Vol. 11, No. 10, (1968). 
12. Simpson, R. L., Moffat, R. J., and Kays, W. M., "The Turbulent Boundary Layer on a Porous Plate: Experimental Skin Friction with Variable Injection and Suction, "Int. Jn. of Heat and Mass Transfer.

13. Julien, H. I., "The Turbulent Boundary Layer on a Porous Plate: Experimental Study of the Effects of a Favorable Pressure Gradient, "Ph.D. thesis, Thermosciences Division, Dept. of Mechanical Engr., Stanford Univ., (1969); available from Univ. Microfilms, Ann Arbor, Mich.

14. Coles, D. E., "The Turbulent Boundary Layer in a Compressible Fluid," RAND Report R-403-PR, (1962).

15. Thielbahr, W. H., "The Turbulent Boundary Layer: Experimental Heat Transfer with Uniform Blowing, Suction and Favorable Pressure Gradients," Ph.D. thesis, Dept. of Mechanical Engr., Stanford Univ., (1969); available from Univ. Microfilms, Ann Arbor, Mich.

16. Kline, S. J., and McClintock, F. A., "Describing Uncertainties in Single Sample Experiments," Mech. Engr., (1953).

17. Van Driest, E. R., "On Turbulent Flow Near a Wall," Jn. of Aero. Science, Vol. 23, p. 1007, (1956). 
Table 1

Run No. 73068

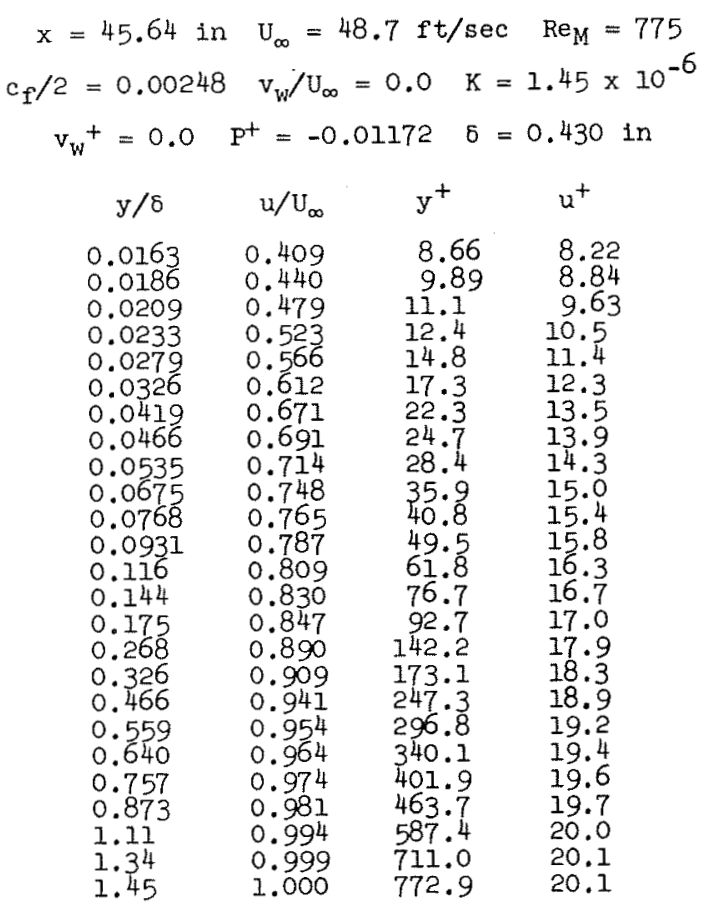

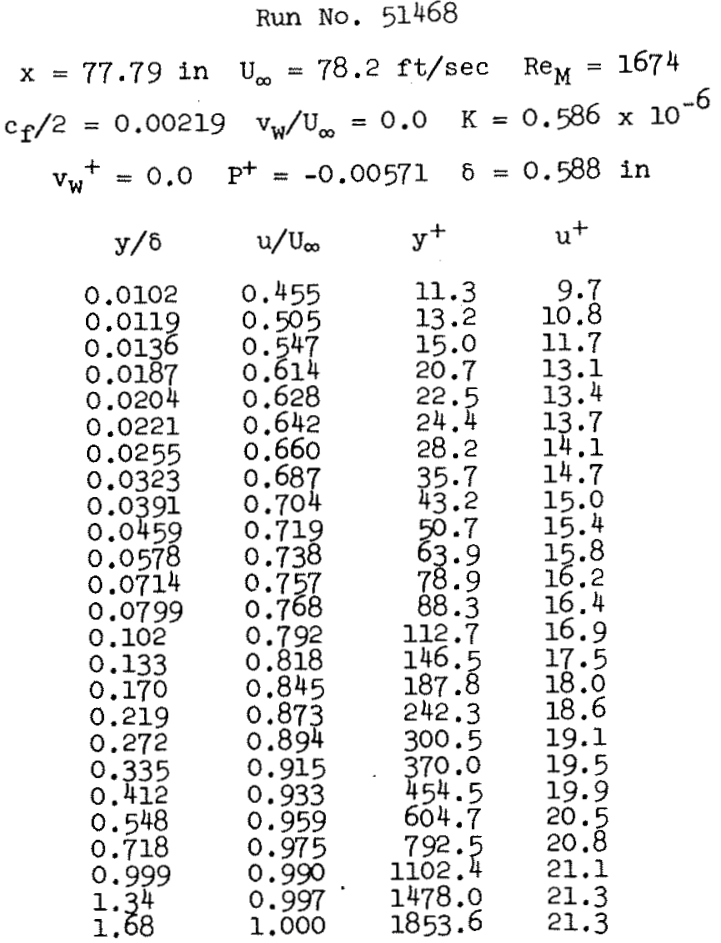

Run No. 80768

Run No. 52868

$x=49.63$ in $U_{\infty}=55.4 \mathrm{ft} / \mathrm{sec} \quad R_{M}=353$

$x=85.79 U_{\infty}=91.4 \mathrm{ft} / \mathrm{sec} \quad \operatorname{Re}_{M}=734$

$c_{f} / 2=0.00310 \quad v_{W} / u_{\infty}=-0.00205 \quad K=1.51 \times 10^{-6}$ $c_{f} / 2=0.00302 \quad v_{W} / U_{\infty}=-0.00204 \quad K=0.573 \times 10^{-6}$ $\mathrm{v}_{\mathrm{w}}^{+}=-0.0368 \quad \mathrm{P}^{+}=-0.00874 \quad 6=0.243$

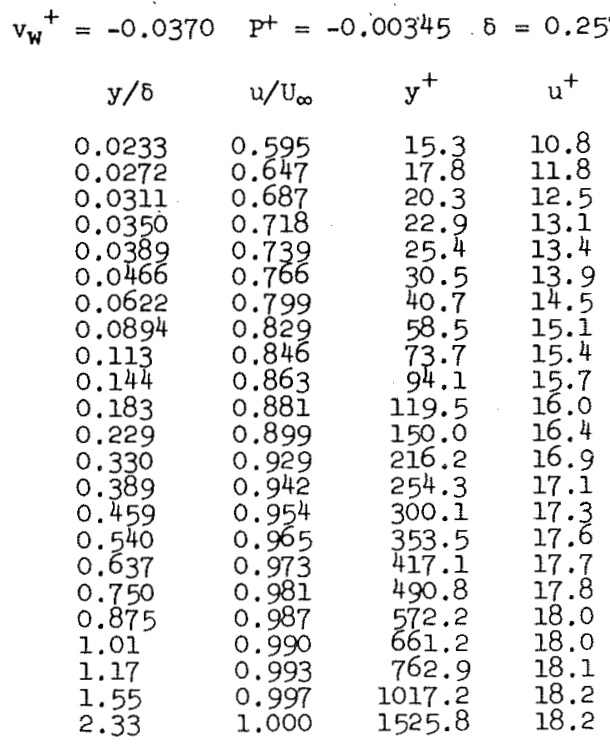


Table 1 (Continued)

Run No. 41268

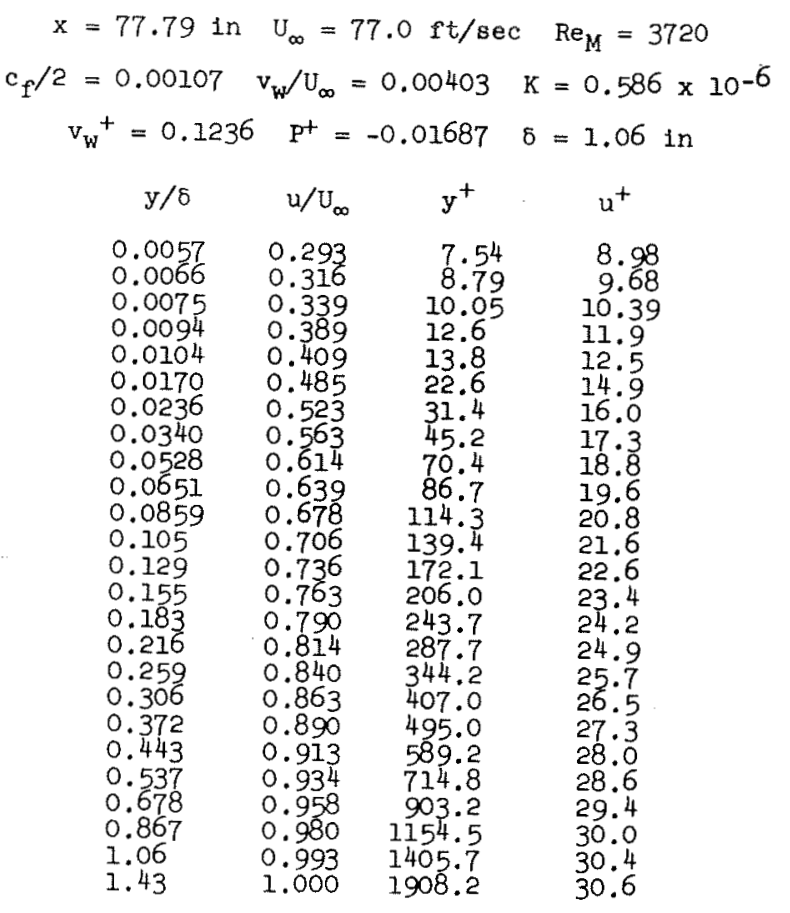

Run No. 82068

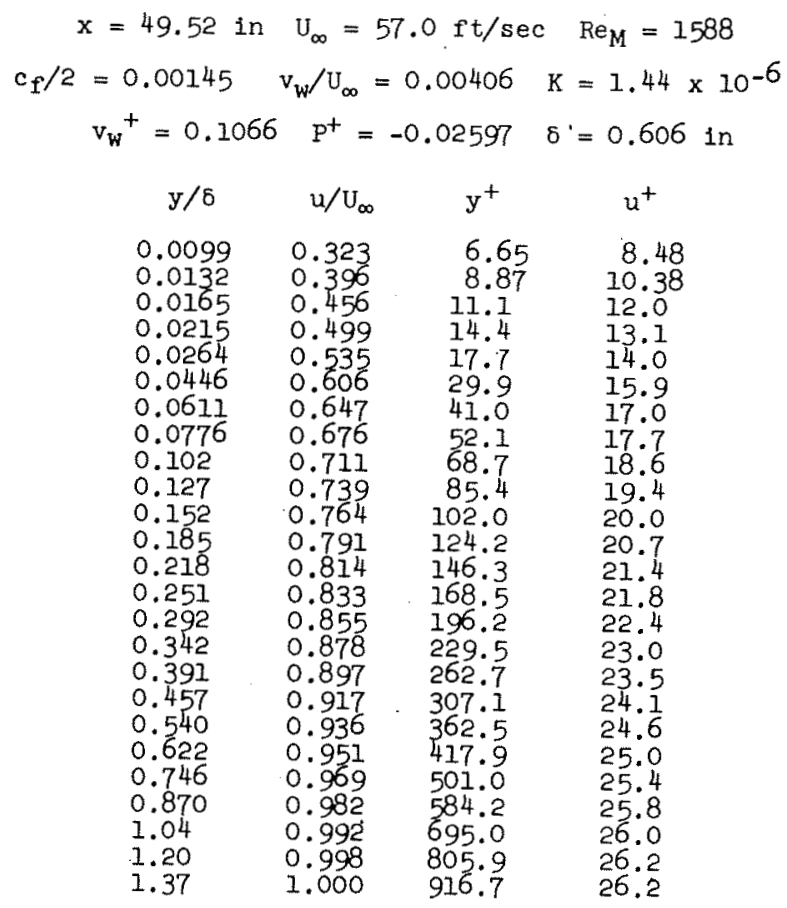




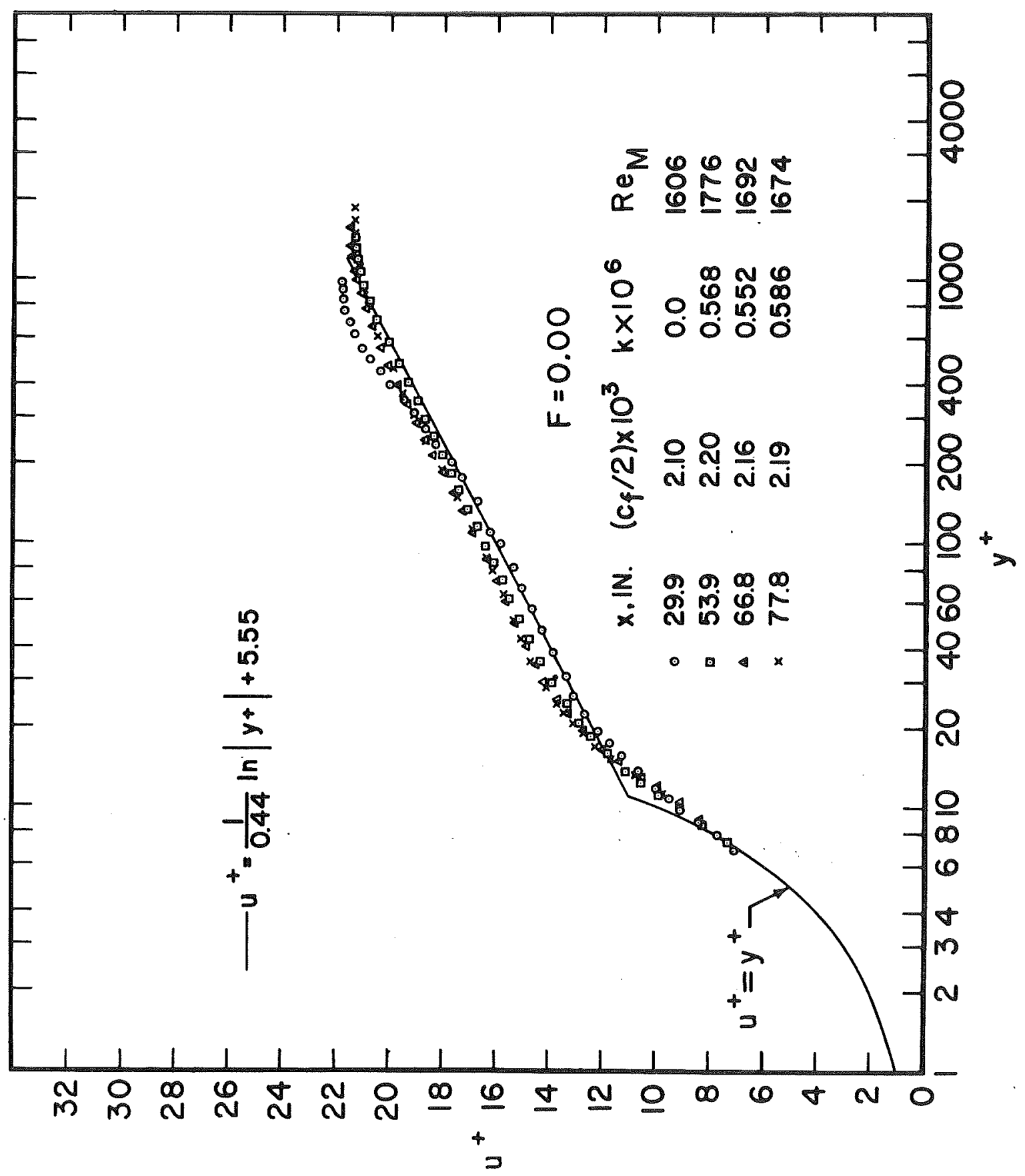

Figure 1. Mean velocity profiles for $F=0.00$ with $K=0.57 \times 10^{-6}$ $-24-$ 


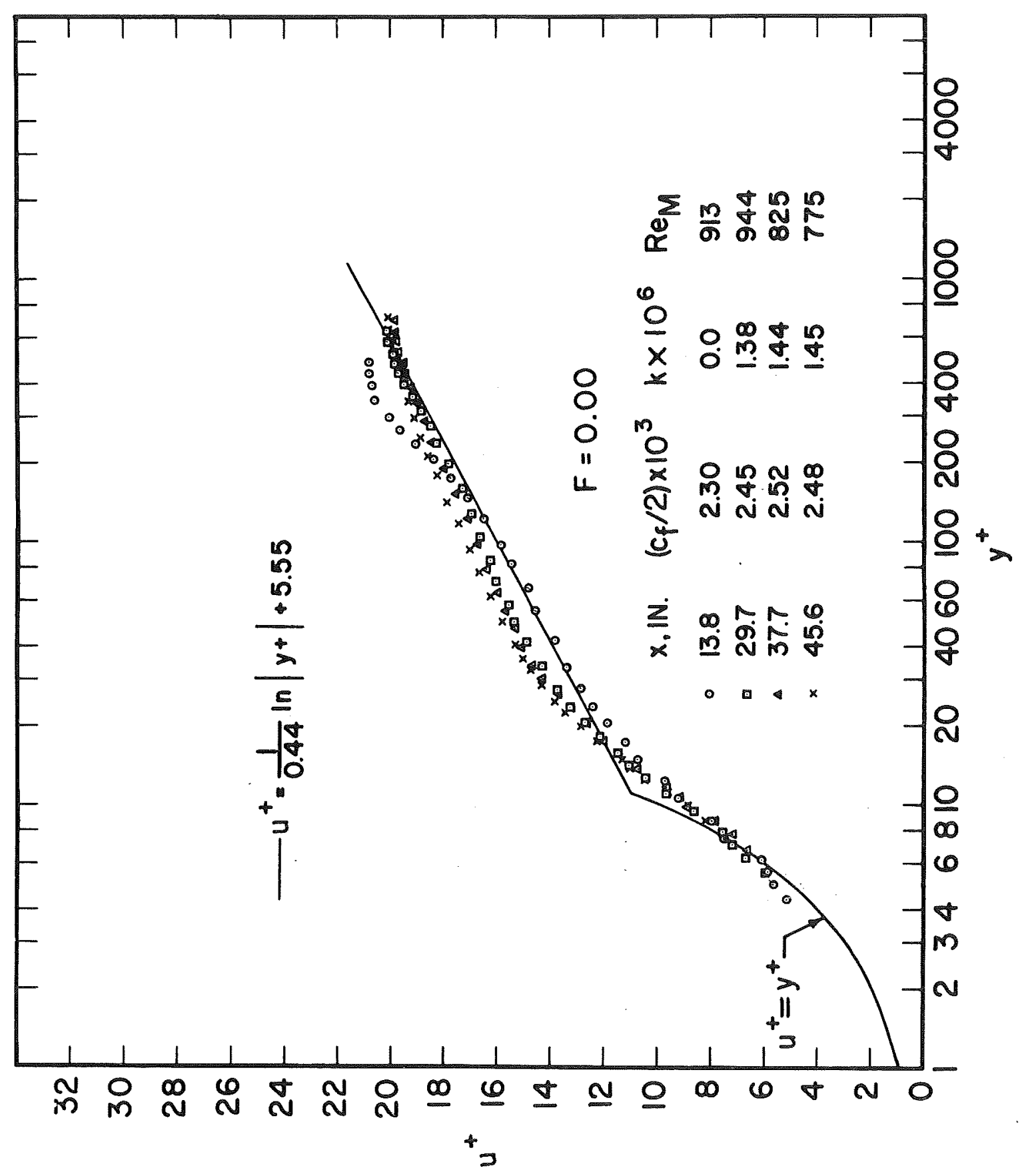

Figure 2. Mean velocity profiles for $F=0.00$ with $K=1.45 \times 10^{-6}$ $-25-$ 


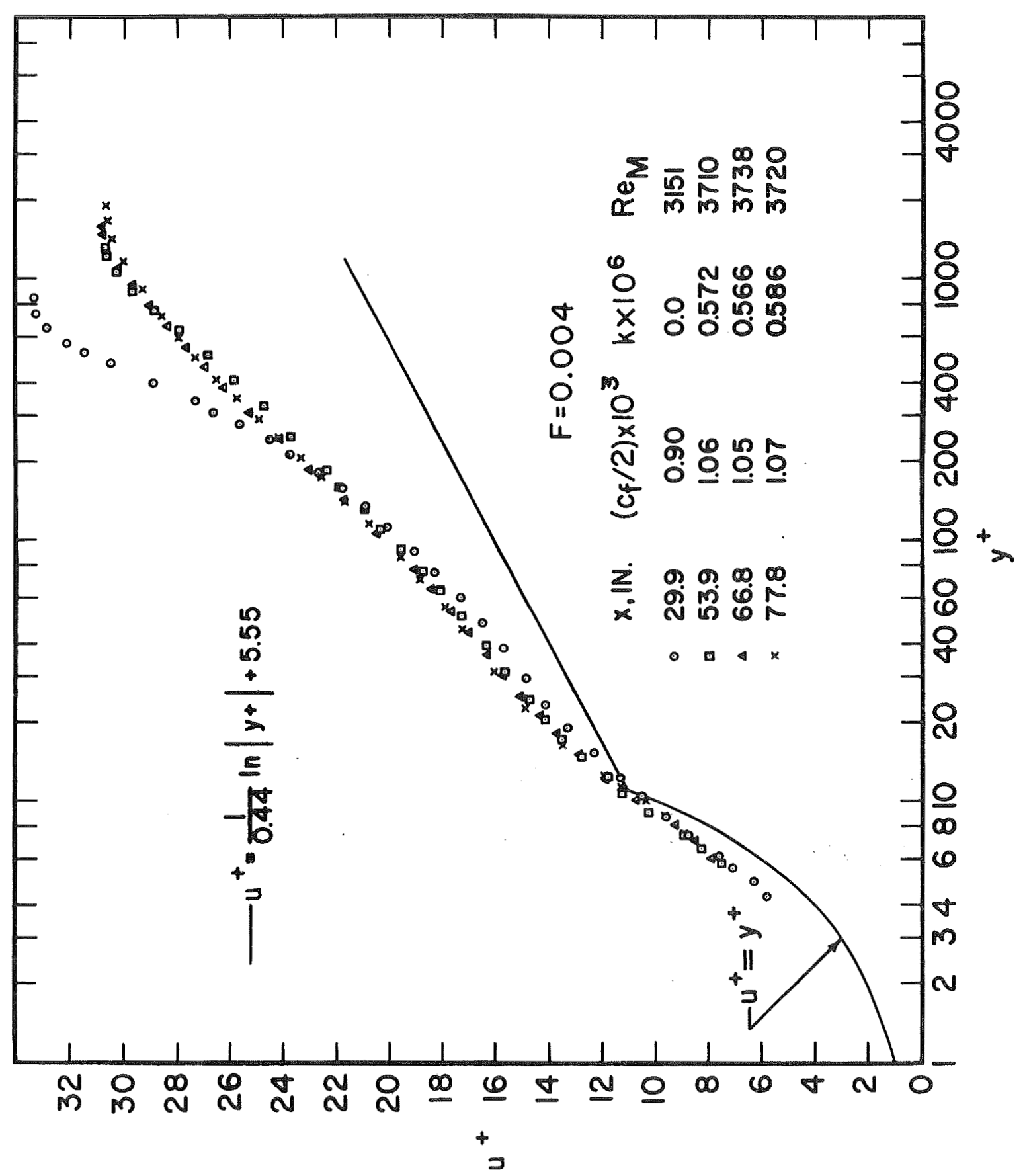

Figure 3. Mean velocity profiles for $\mathrm{F}=0.004$ with $\mathrm{K}=0.57 \times 10^{-6}$ -26 - 


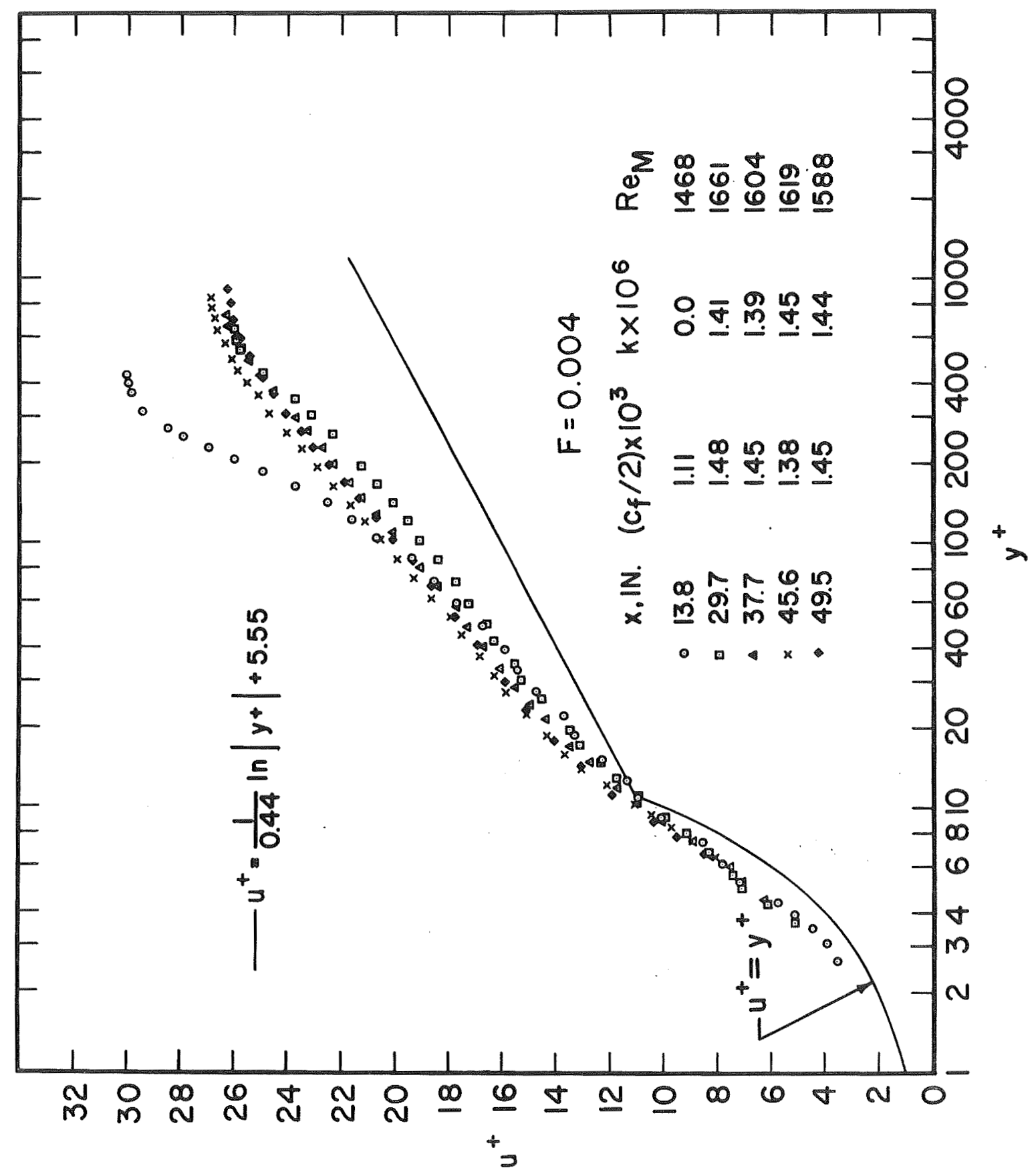

Figure 4. Mean velocity profiles for $F=0.004$ with $K=1.45 \times 10^{-6}$ $-27-$ 


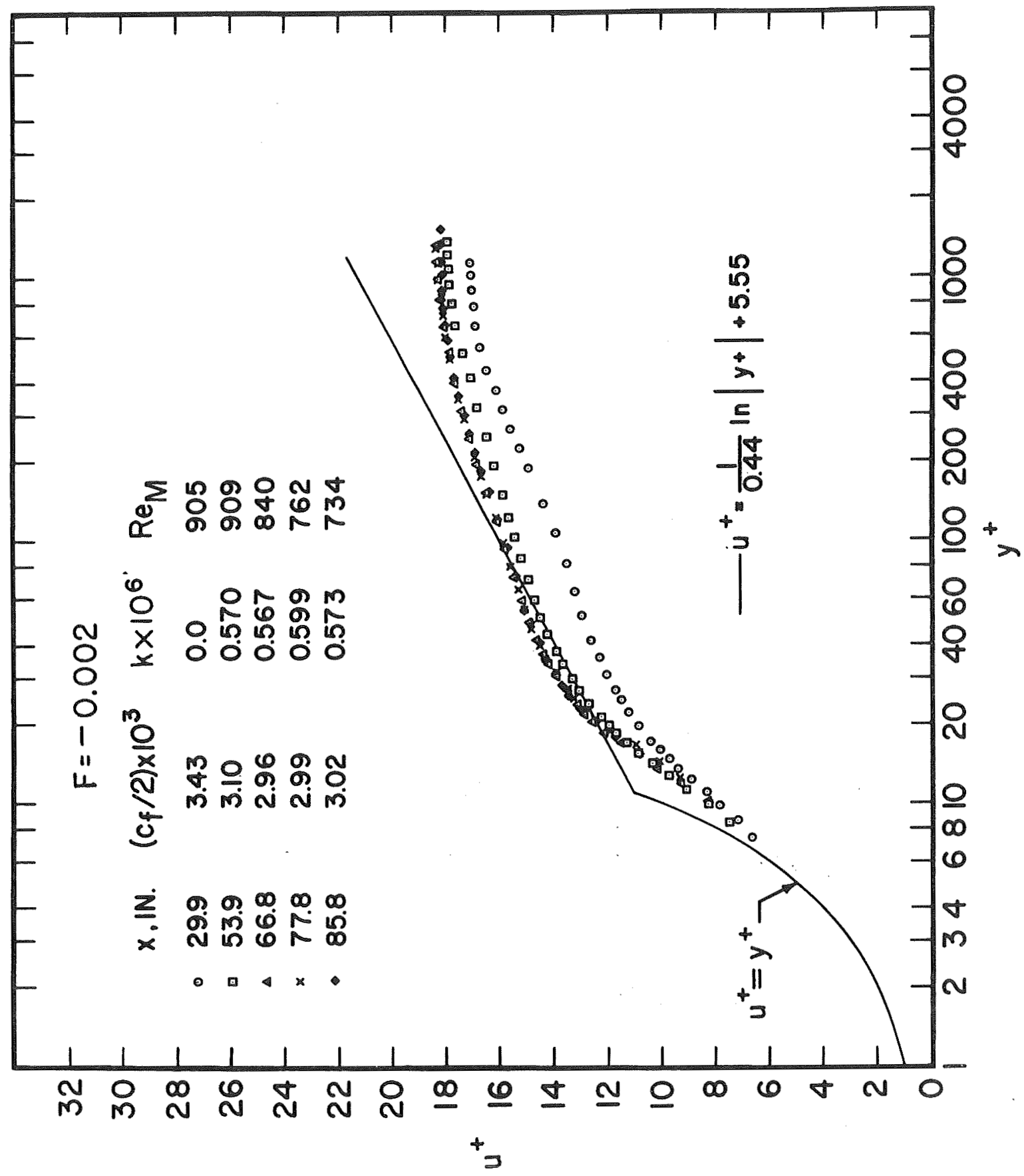

Figure 5. Mean velocity profiles for $\mathrm{F}=-0.002$ with $\mathrm{K}=0.57 \times 10^{-6}$ $-28-$ 


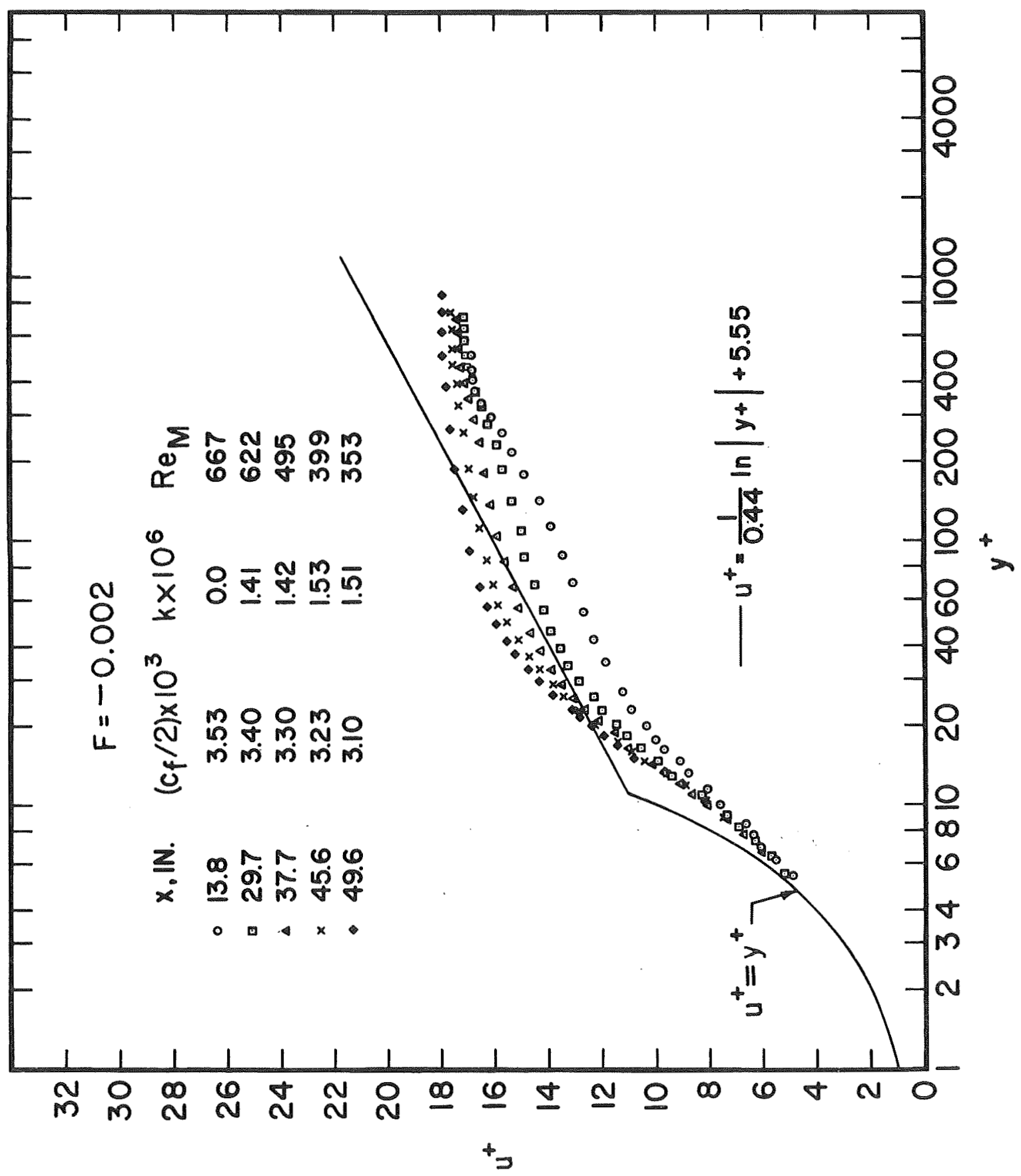

Figure 6. Mean velocity profiles for $F=-0.002$ with $K=1.45 \times 10^{-6}$ $-29-$ 